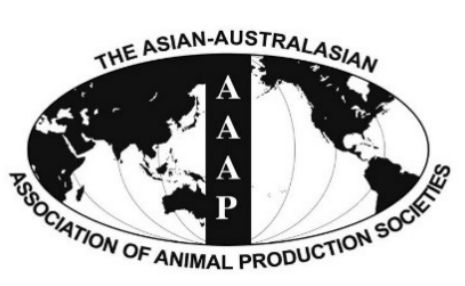

\title{
Effect of Feeding a Mixed Microbial Culture Fortified with Trace Minerals on the Performance and Carcass Characteristics of Late-fattening Hanwoo Steers: A Field Study
}

\author{
W. S. Kwak*, Y. I. Kim, S. M. Lee', Y. H. Lee, and D. Y. Choi \\ Division of Food Biosciences, College of Health and Medical Life Sciences, \\ Konkuk University, Chungju 380-701, Korea
}

\begin{abstract}
This study was conducted to determine the effects of feeding a trace minerals-fortified microbial culture (TMC) on the performance and carcass characteristics of late-fattening Hanwoo steers. A mixture of microbes $(0.6 \%$ [v/w] of Enterobacter sp., Bacillus sp., Lactobacillus sp., and Saccharomyces sp.) was cultured with $99 \%$ feedstuff for ensiling and $0.4 \%$ trace minerals (zinc, selenium, copper, and cobalt). Sixteen late-fattening steers (mean age, 21.8 months) were allocated to two diets: a control diet (concentrate mix and rice straw) and a treated diet (control diet $+3.3 \% \mathrm{TMC}$ ). At a mean age of 31.1 months, all the steers were slaughtered. The addition of TMC to the diet did not affect the average daily weight gain of the late fattening steers, compared with that of control steers. Moreover, consuming the TMC-supplemented diet did not affect cold carcass weight, yield traits such as back fat thickness, longissimus muscle area, yield index or yield grade, or quality traits such as meat color, fat color, texture, maturity, marbling score, or quality grade. However, consumption of a TMC-supplemented diet increased the concentrations of zinc, selenium, and sulfur $(\mathrm{p}<0.05)$ in the longissimus muscle. With respect to amino acids, animals consuming TMC showed increased $(\mathrm{p}<0.05)$ concentrations of lysine, leucine, and valine among essential amino acids and a decreased $(\mathrm{p}<0.05)$ concentration of proline among non-essential amino acids. In conclusion, the consumption of a TMC-supplemented diet during the late-fattening period elevated the concentrations of certain trace minerals and essential amino acids in the longissimus muscle, without any deleterious effects on performance and other carcass characteristics of Hanwoo steers. (Key Words: Microbial Culture, Trace Mineral, Carcass, Meat Quality, Steer, Hanwoo)
\end{abstract}

\section{INTRODUCTION}

It is well known that directly feeding microbes to animals is beneficial to animal agriculture production (Kwak and Kang, 2006; Yang et al., 2006; Zhou et al., 2009). Benefits derived from the consumption of these microbes include improved ruminal acidosis prevention, gut microbial balance, feed intake, weight gain, and feed efficiency in ruminants (Yoon and Stern, 1995; Krehbiel et al., 2003). For instance, direct consumption of a yeast culture increased feed intake in lactating Holstein cows

\footnotetext{
* Corresponding Author: W. S. Kwak. Tel: +82-43-840-3521, Fax:+82-43-851-8675, E-mail: wsk@kku.ac.kr

${ }^{1}$ Department of Animal Science, Kyungpook National University, Sangju 742-711, Korea.

Submitted Feb. 5, 2015; Revised Apr. 19, 2015; Accepted May 26, 2015
}

(Williams et al., 1991; Robinson and Garrett, 1999) and Hereford steers (Adams et al., 1981), resulting in improved animal performance.

The use of microorganisms in animal diets has also been shown to improve mineral balance. For instance, Yoon and Stern (1995) reported that yeast culture supplementation improved the retention of minerals (potassium, copper, and iron) in growing ruminants. Moreover, Cole et al. (1992) reported that lambs fed yeast culture tended to have a better balance of zinc and iron, and the dietary addition of a mixed microbial (Bacillus and Saccharomyces) culture was effective in improving mineral bioavailability to beef steers (Kwak et al., 2012). Furthermore, feeding a diet supplemented with certain trace minerals and a mixture of microbes (Bacillus and Saccharomyces) improved the growth, meat yield, and quality of beef steers (Kim et al., 
2007a).

Trace mineral deficiency impairs productivity in ruminants. Dietary trace minerals such as zinc and copper are essential components of enzymes and stimulate cattle growth (National Research Council, 2000). Addition of zinc to cattle diets improved growth and carcass characteristics (Greene et al., 1988; Spears and Kegley, 2002). Copper deficiency frequently occurs because antagonists such as molybdenum, sulfur, and iron are frequently high in ruminant diets and reduce the bioavailability of copper (Underwood and Suttle, 1999). Accordingly, the use of either supplemented trace minerals or mixed microbes, or a combination of these, has been shown to positively affect ruminant performance. Supplementation with mixed microbial cultures is a conventional practice at the majority of Hanwoo farms in Korea. If the culture is fortified with certain deficient trace minerals, an associative effect of these two products could be expected. Therefore, we hypothesized that feeding a trace minerals-fortified microbial culture (TMC) may positively affect the production and meat quality of Hanwoo steers.

Accordingly, this study was conducted to determine the effects of TMC on the growth performance and carcass characteristics of late-fattening Hanwoo steers fed rice straw as the main roughage source.

\section{MATERIALS AND METHODS}

\section{Preparation of the mixed microbial culture}

The organisms in the mixed microbial inoculum used in this experiment were isolated and identified previously in our lab (Kim et al., 2007b; 2008). The inoculum included Enterobacter ludwigii KU201-3, Bacillus cereus KU206-3, Bacillus subtilis KU3, Lactobacillus plantarum KU5, and Saccharomyces cerevisiae; these strains were each inoculated at $0.12 \%$. Bacillus sp. and Enterobacter sp. were cultured in plate count broth (5 g casein, $2.5 \mathrm{~g}$ yeast extract, and $1 \mathrm{~g} / \mathrm{L}$ dextrose) at $36^{\circ} \mathrm{C}$ for $24 \mathrm{~h}$; Lactobacillus sp. was cultured in de Man, Rogosa and Sharpe (MRS) broth (0881, Difco Laboratories Inc., Detroit, MI, USA) at $36^{\circ} \mathrm{C}$ for $24 \mathrm{~h}$, and Saccharomyces sp. was cultured in yeast malt broth (0711, Difco Laboratories Inc., USA) at $30^{\circ} \mathrm{C}$ for $48 \mathrm{~h}$.

These microbes $(0.6 \% \mathrm{v} / \mathrm{w})$ were inoculated into a mixture of $19.6 \%$ ground corn grain, $16.0 \%$ soybean meal, $24.4 \%$ defatted rice bran, $20.0 \%$ bentonite, $12.2 \%$ spent mushroom substrate, $3.3 \%$ jujube (low quality), $2.5 \%$ molasses, $1.6 \% \mathrm{MgO}$, and $0.4 \%$ trace minerals, fermented for 5 days, and dried. The chemical composition is presented in Table 1. The rice straw used was freshly baled.

The control diet (formulated concentrate mix +rice straw) lacked trace minerals, as shown in Table 2. Dietary zinc and copper levels in the late-fattening period were lower than
Table 1. Chemical compositions of feeds fed to fattening Hanwoo steers $^{1}(\%$, DM basis $)$

\begin{tabular}{|c|c|c|c|}
\hline Item & $\begin{array}{c}\text { Concentrate } \\
\text { mix }\end{array}$ & $\begin{array}{l}\text { Rice } \\
\text { straw }\end{array}$ & $\begin{array}{c}\text { Microbial } \\
\text { culture }^{2}\end{array}$ \\
\hline DM & 87.0 & 65.3 & 84.8 \\
\hline Crude protein & 13.0 & 4.0 & 16.7 \\
\hline Ether extract & 3.1 & 1.3 & 0.5 \\
\hline Neutral detergent fiber & 30.5 & 70.7 & 26.1 \\
\hline Acid detergent fiber & 15.9 & 42.6 & 16.0 \\
\hline Crude ash & 7.3 & 11.3 & 26.8 \\
\hline
\end{tabular}

\section{DM, dry matter.}

${ }^{1}$ Means of 3 observations.

${ }^{2}$ Mixed microbes $(0.6 \% \mathrm{v} / \mathrm{w})$ were inoculated into the mixture of $19.6 \%$ ground corn grain, $16.0 \%$ soybean meal, $24.4 \%$ defatted rice bran, $20.0 \%$ bentonite, $12.2 \%$ spent mushroom substrate, $3.3 \%$ low quality jujube, $2.5 \%$ molasses, $1.6 \% \mathrm{MgO}$, and $0.4 \%$ trace minerals, fermented for 5 days, and dried.

the National Research Council (2000) requirement of beef cattle. Compounds containing trace minerals such as sodium selenite, zinc sulfate, copper sulfate, and cobalt sulfate were added to the microbial culture to fully satisfy the National Research Council (2000) requirement (1.5-fold requirement for each mineral). For reference, the chemical composition of the control diet was $84.4 \%$ dry matter (DM), $12.1 \%$ crude protein (CP), $2.9 \%$ ether extract (EE), $34.1 \%$ neutral detergent fiber (NDF), $18.2 \%$ acid detergent fiber (ADF), and $7.5 \%$ crude ash.

\section{Animals and treatments}

All animal care protocols were approved by the Konkuk University Institutional Animal Care and Use Committee. Sixteen late-fattening Hanwoo steers (mean age, 21.8 months; mean body weight [BW], $514 \pm 7.5 \mathrm{~kg}$ ) were randomly assigned to four pens. Each pen measured $50 \mathrm{~m}^{2}$ in area $(5 \mathrm{~m} \times 10 \mathrm{~m})$.

The steers were fed one of two diets: a control diet (formulated concentrate mix and rice straw), and a treated diet (control diet $+3.3 \%$ TMC). The microbial culture was fed to the steers during the late-fattening period. The concentrate mix was freely accessed at a rate of $9 \mathrm{~kg}$ per day, and rice straw was restricted to $1.2 \mathrm{~kg} / \mathrm{d}$ (as-fed basis). Feed with a TMC topdressing was provided twice a day (07:00 and 18:00). Animals always had free access to fresh water. The total feeding period was 9.3 months. The BW of the steers was measured monthly throughout the feeding

Table 2. Zinc and Copper levels in the control diet (dry matter basis)

\begin{tabular}{lcc}
\hline & $\begin{array}{c}\text { Control diet } \\
(\mathrm{mg} / \mathrm{kg})\end{array}$ & $\begin{array}{c}\text { Requirement of beef cattle } \\
(\mathrm{mg} / \mathrm{kg})^{1}\end{array}$ \\
\hline Zinc & 20.0 & 30.0 \\
Copper & 4.5 & 10.0 \\
\hline 1 Cited from &
\end{tabular}

${ }^{1}$ Cited from National Research Council (2000). 
trial, using a scale (BI-2RB, CAS, Yangju, Korea).

\section{Carcass characteristics}

At a mean age of 31.1 months, the steers were withdrawn from the experimental diets $24 \mathrm{~h}$ before slaughter. Following a 48-h carcass chill, the yield and quality grade of each carcass was measured using Korean carcass grading standards, specified in the Korean Livestock Enforcement Regulation (Korean Ministry of Agriculture and Forest, 2007). Quality grades were classified as $1^{++}$(very high quality), $1^{+}, 1,2$, and 3 (low quality). Back fat thickness and the longissimus muscle area were measured at the 13 th rib. Yield index was calculated as follows: yield index $=68.184-(0.625 \times$ back fat thickness $[\mathrm{mm}])+\left(0.130 \times\right.$ longissimus muscle area $\left.\left[\mathrm{cm}^{2}\right]\right)-(0.024 \times$ cold carcass weight $[\mathrm{kg}])+3.23$. Yield grades were classified as $\mathrm{A}$ (high yield), $\mathrm{B}$, and $\mathrm{C}$ (low yield): grade $\mathrm{A}=$ higher than 67.5; grade $\mathrm{B}=$ higher than 62.0 and lower than 67.5 ; and grade $\mathrm{C}=$ lower than 62.0 . The grading ranged between 1 and 27, with higher numbers indicating better quality: marbling $(1=$ devoid, $27=$ abundant $)$; meat color $(1=$ bright cherry red, $7=$ extremely dark red); fat color $(1=$ white, $7=$ dark yellow); texture $(1=$ soft, $3=$ firm $)$; and maturity $(1$ = youthful, 9 = mature $)$.

\section{Chemical and microbial analyses}

Representative samples of the test feeds that were fed to the Hanwoo steers were collected and stored at $-20^{\circ} \mathrm{C}$ for later analysis. Immediately before analysis, all samples were dried and ground to pass through a 1-mm filter by using a sample mill (Cemotec, Tecator, Skanor, Sweden). The DM fraction was quantified by drying the samples at $60^{\circ} \mathrm{C}$ for $48 \mathrm{~h}$ to reach a constant weight. The CP, EE, NDF, $\mathrm{ADF}$, and crude ash contents were determined by the AOAC (2000) method.

The longissimus muscle was removed at the 12th to 13th rib, retained from each steer, and frozen until later analysis. For mineral analysis of the rib muscle, samples were analyzed for calcium, phosphorus, magnesium, potassium, sodium, sulfur, manganese, zinc, selenium, copper, iron, cobalt, and molybdenum by inductively coupled argon plasma emission spectroscopy (ICP-OES 5300DV, Perkin Elmer, Billerica, MA, USA), as described by Braselton et al. (1997).

Microbial analyses of the samples (sample size, $25 \mathrm{~g}$ ) were conducted according to the AOAC (2000) method. Specifically, the total bacterial count was determined on plate count agar (Difco Laboratories Inc., USA) after incubation at $30^{\circ} \mathrm{C}$ for $48 \mathrm{~h}$. The lactic acid bacterial count was determined using MRS agar plates (Difco Laboratories Inc., USA) after incubation at $36^{\circ} \mathrm{C}$ for $24 \mathrm{~h}$. The yeast count was determined on yeast malt agar plates (Difco Laboratories Inc., USA) after incubation at $36^{\circ} \mathrm{C}$ for $48 \mathrm{~h}$. The mixed microbial culture contained each species at a viable cell concentration in excess of $10^{6} \mathrm{cfu} / \mathrm{g}$.

\section{Statistical analysis}

Data were subjected to one-way analysis of variance by using the general linear model procedure (Statistix7, 2000). The means of the control diet and the treated diet were compared using the Student's t-test (Statistix7, 2000). Significant differences were detected at $\mathrm{p}<0.05$.

\section{RESULTS AND DISCUSSION}

\section{Body weight gain and feed intake}

Consumption of a TMC-supplemented diet did not affect steer growth rates significantly, although it increased the average BW by $26 \mathrm{~kg}$ (14\% of the control group weight) and average daily BW gain by $0.09 \mathrm{~kg}$ (Table 3 ). Compared to the control group, the TMC-fed group showed a relatively narrow range of BW gain, indicating the desirably consistent growth of individual steers. In terms of feed intake, the concentrate mix intake was higher in the TMCfed group than in the control group, although the rice straw intake was similar. This increase in concentrate mix intake appears to be responsible for the increased $\mathrm{BW}$ gain observed in TMC-fed steers.

The feed intake mechanism thus appears to be more complicated than expected because many factors can

Table 3. Growth and feed intake of late fattening Hanwoo steers fed trace mineral-fortified microbial culture (TMC)

\begin{tabular}{|c|c|c|c|c|}
\hline Item & Control (kg) & TMC added $(\mathrm{kg})$ & SE & p-value \\
\hline \multicolumn{5}{|l|}{ Growth $^{1}$} \\
\hline Initial wt (21.8 mo old) & 517 & 512 & 15 & 0.72 \\
\hline Final wt (31.1 mo old) & 698 & 719 & 19 & 0.31 \\
\hline Gain & 181 & 207 & 16 & 0.12 \\
\hline Average daily gain & 0.63 & 0.72 & 0.05 & 0.12 \\
\hline Range & $0.45-0.87$ & $0.67-0.76$ & - & - \\
\hline \multicolumn{5}{|l|}{ Feed intake ${ }^{2}$} \\
\hline Concentrate mix & 9.1 & 9.5 & 0.2 & 0.12 \\
\hline Rice straw & 1.2 & 1.2 & 0.1 & 0.12 \\
\hline
\end{tabular}

SE, standard error.

${ }^{1}$ Means of 8 observations. ${ }^{2}$ Means of 2 observations and on a wet basis. 
influence it. Deficiency of copper resulted in reduced feed intake and subsequently reduced growth (National Research Council, 2005). Deficiency of zinc reduced feed intake, growth, and feed efficiency and impaired immune function (National Research Council, 2005). An impaired immune system, resulting from deficiency of certain minerals, generally reduces feed intake and growth (Adams, 2001). Therefore, supplementation of minerals and microbes in the diet may have led to recovery from conditions of an impaired immune system and mineral deficiency to consequently improve feed intake, leading to improved BW gain. In addition, the TMC itself showed high palatability, possibly due to the included flavor enhancers such as molasses and jujube. The highly palatable TMC pellets may have induced more frequent consumption of the concentrate mix, resulting in increased feed intake. Alternatively, the highly palatable TMC pellets may have increased rumen microbial mass and further stimulated feed fermentation and digestion, thereby possibly acting as a positive feedback system to improve feed intake, as suggested by Adams (2001).

\section{Evaluation of the quantity and quality of meat}

Carcass characteristics: The consumption of TMCsupplemented feed tended $(\mathrm{p}=0.09)$ to increase the cold carcass weight by an average of $24 \mathrm{~kg}$ and did not affect yield traits such as dressing percentage, back fat thickness, longissimus muscle area, yield index, or yield grade.
Moreover, quality traits such as marbling score, meat color, fat color, texture, maturity, or quality grade were not affected by TMC-supplementation (Table 4). The favorable increase in weight observed in steers fed the TMCsupplemented diet resulted in greater carcass weights. The sale price was about $4.1 \%$ higher for the steers fed TMC than for the control steers. In contrast, Mir and Mir (1994) reported that feeding live yeast to Hereford steers did not affect carcass characteristics such as carcass weight, dressing percentage, backfat thickness, loin eye area, and yield index. Moreover, Kim et al. (2007a) reported that feeding a $1 \%$ microbial culture to Hanwoo steers had no effect on meat characteristics. However, dietary supplementation of zinc and other trace minerals has been shown to positively affect cattle performance and increase carcass weight (Spears and Kegley, 2002; Spears, 2003). In another study (Kim and Lee, 2014) on feeding black sugar and mineral premix to fattening Hanwoo steers, cold carcass weight was found to increase with no differences in yield and quality traits. In the present study, the combined use of microbes and trace minerals tended to improve carcass weight.

Meat mineral profile: The effect of feeding TMC on the meat mineral profiles of steers is presented in Table 5. The treatment significantly affected $(\mathrm{p}<0.05)$ the mineral concentrations in the longissimus muscle. Compared with the control steers, TMC-fed steers displayed increased concentrations of zinc and selenium $(\mathrm{p}<0.05)$, but showed

Table 4. Meat characteristics of Hanwoo steers fed with trace mineral-fortified microbial culture (TMC) during the late fattening period ${ }^{1}$

\begin{tabular}{|c|c|c|c|c|}
\hline Item & Control & TMC added & $\mathrm{SE}$ & p-value \\
\hline Cold carcass weight (kg) & 406 & 430 & 13 & 0.09 \\
\hline \multicolumn{5}{|l|}{ Yield traits } \\
\hline Dressing $(\%)$ & 62.3 & 64.3 & 1.3 & 0.14 \\
\hline Backfat thickness (mm) & 12.6 & 15.4 & 2.5 & 0.29 \\
\hline Longissimus muscle area $\left(\mathrm{cm}^{2}\right)$ & 79.8 & 82.3 & 4.6 & 0.60 \\
\hline Yield index & 64.1 & 62.2 & 1.8 & 0.31 \\
\hline Yield grade ${ }^{2}$ & 2.00 & 2.25 & 0.40 & 0.54 \\
\hline \multicolumn{5}{|l|}{ Quality traits } \\
\hline Marbling score ${ }^{3}$ & 4.6 & 4.1 & 0.9 & 0.59 \\
\hline Meat color ${ }^{4}$ & 4.63 & 4.88 & 0.23 & 0.29 \\
\hline Fat color ${ }^{5}$ & 3.25 & 3.00 & 0.25 & 0.34 \\
\hline Texture $^{6}$ & 1.75 & 1.63 & 0.26 & 0.64 \\
\hline Maturity $^{7}$ & 1.88 & 2.00 & 0.13 & 0.34 \\
\hline \multicolumn{5}{|l|}{ Quality grade $(\%)$} \\
\hline $1^{++}$, heads & $1(12.5)$ & 0 & - & - \\
\hline $1^{+}$, heads & $2(25.0)$ & $3(37.5)$ & - & - \\
\hline 1, heads & $1(12.5)$ & $2(25.0)$ & - & - \\
\hline 2 , heads & $4(50.0)$ & $3(37.5)$ & - & - \\
\hline Sale price (million won) & 6.27 & 6.53 & 0.49 & 0.60 \\
\hline
\end{tabular}

SE, standard error.

${ }^{1}$ Means of 8 observations. ${ }^{2}$ Scored: grade $A=1$ (lean), $B=2, C=3$ (fat). ${ }^{3}$ Scored: grade $1=$ poor, grade $9=$ excellent

${ }^{4}$ Scored: grade $1=$ scarlet, grade $7=$ dark red. ${ }^{5}$ Scored: grade $1=$ white, grade $7=$ yellow. ${ }^{6}$ Scored: grade $1=$ good, grade $3=$ bad .

${ }^{7}$ Scored: grade $1=$ fully mature, grade $9=$ least mature. ${ }^{8}$ Scored: grade $1^{++}=1$ (best), $1^{+}=2,1=3,2=4,3=5$ (poorest). 
Table 5. Trace mineral composition (fresh basis) of longissimus muscle of Hanwoo steers fed with trace mineral-fortified microbial culture (TMC) during the late fattening period ${ }^{1}$

\begin{tabular}{lcccc}
\hline Item & $\begin{array}{c}\text { Control } \\
(\mathrm{ppm})\end{array}$ & $\begin{array}{c}\text { TMC added } \\
(\mathrm{ppm})\end{array}$ & $\mathrm{SE}$ & $\mathrm{p}$-value \\
\hline Zinc & $69.0^{\mathrm{a}}$ & $79.7^{\mathrm{b}}$ & 4.8 & 0.0425 \\
Copper & 1.36 & 1.49 & 0.11 & 0.2618 \\
Selenium & $0.30^{\mathrm{a}}$ & $0.44^{\mathrm{b}}$ & 0.05 & 0.0195 \\
Iron & 25.2 & 29.9 & 2.3 & 0.0710 \\
Manganese & 0.20 & 0.23 & 0.02 & 0.1885 \\
Cobalt & 0.11 & 0.13 & 0.01 & 0.1102 \\
Molybdenum & 0.03 & 0.04 & 0.01 & 0.4860 \\
Total & 97.0 & 111.4 & 6.9 & 0.0734 \\
\hline
\end{tabular}

SE, standard error.

${ }^{1}$ Means of 8 observations.

${ }^{a, b}$ Means with different superscripts within the same row are significantly different $(\mathrm{p}<0.05)$

similar concentrations of copper, iron, manganese, cobalt, and molybdenum within the longissimus muscle. More specifically, the longissimus muscle of steers fed the TMC contained $15.5 \%$ higher zinc, $46.7 \%$ higher selenium, and $14.8 \%$ higher $(\mathrm{p}=0.07)$ total trace mineral concentrations than those observed in the longissimus muscle of the control steers. The longissimus muscle of steers fed TMC had consistently higher concentrations of most of the trace minerals compared to those in the longissimus muscle of the control steers. The range of mineral concentrations was intermediate to the values reported by Westing et al. (1985) and Williams et al. (1983).

The control diet in this study contained more potassium, sodium, iron, and manganese, and less magnesium, zinc, and selenium (data not presented) than the dietary requirement specified in the Korean Feeding Standard Establishment Council (2007) and National Research Council (2000) guidelines. Dietary incorporation of these deficient minerals for TMC-fed steers resulted in higher retention in the longissimus muscle. Similarly, Yoon and Stern (1995) reported that yeast culture supplementation improved the retention of minerals (potassium, copper, and iron) in growing ruminants. Moreover, Cao et al. (2000) reported that zinc supplementation in ruminant diets that were deficient in zinc resulted in increased zinc content in the muscle of the animals. When probiotics with bentonite were fed to steers for 22 months, the longissimus muscle showed higher concentrations of zinc (49\%), copper (100\%), and iron (34.5\%) (Kwak et al., 2012). The inconsistencies between the results of these studies and those of the present investigation seem to be due to different dietary factors and feeding conditions. In the present study, the addition of copper sulfate to the feed did not increase copper concentration in the muscle, possibly because dietary supplementation of sulfur reduces copper absorption (Spears, 2003). That being said, the muscle selenium content significantly increased even though dietary supplementation of sulfur reduces the bioavailability of selenium (Spears, 2003).

With respect to the major minerals within the longissimus muscle (Table 6), TMC-supplementation did not affect concentrations of calcium, phosphorus, magnesium, potassium, and sodium, but increased the concentration of sulfur $(p<0.0005)$, relative to that in the control. This phenomenon was attributed to the dietary sulfur contributed by sulfate forms of zinc, copper, and cobalt in the feed.

Meat amino acid profile: Effect of the TMCsupplemented dietary treatment on the amino acid composition of the longissimus muscle is presented in Table 7. The amino acid composition of the longissimus muscle was affected by the dietary treatment $(\mathrm{p}<0.05)$. TMC consumption increased $(p<0.05)$ the concentrations of lysine, leucine, and valine, and tended $(p<0.08)$ to increase the concentration of methionine among the essential amino acids and decreased $(p<0.05)$ the concentration of proline among the non-essential amino acids. Dietary supplementation of sulfur in the sulfate form of trace minerals apparently resulted in the increased muscular retention of the sulfur amino acid methionine. However, another sulfur amino acid, cysteine, which can be synthesized from methionine (National Research Council, 1998), was not affected by this treatment. Additional energy supply, apparently by increased feed intake in the present study, can improve amino acid synthesis in the rumen by increasing microbial growth, and improve amino acid flow into the lower digestive tract as suggested by Asplund (1994). When additional nitrogen and sulfur are available in the rumen, limiting essential amino acids can be synthesized by the rumen microbes. Microbial protein is a high-quality protein because it has higher concentration of essential amino acids than does vegetable protein (Ishler et al., 1996). This increase in microbial amino acid digestion and retention likely induced increases in the concentrations

Table 6. Major mineral composition (fresh basis) of longissimus muscle of Hanwoo steers fed with trace mineral-fortified microbial culture (TMC) during the late fattening period ${ }^{1}$

\begin{tabular}{lcccc}
\hline Item & $\begin{array}{c}\text { Control } \\
(\mathrm{ppm})\end{array}$ & $\begin{array}{c}\text { TMC added } \\
(\mathrm{ppm})\end{array}$ & SE & p-value \\
\hline Calcium & 71.8 & 77.3 & 5.4 & 0.3854 \\
Phosphorus & 606 & 542 & 119 & 0.6593 \\
Magnesium & 289 & 299 & 13 & 0.4740 \\
Potassium & 2,776 & 3,089 & 202 & 0.1588 \\
Sodium & 526 & 515 & 28 & 0.7007 \\
Sulfur & $7,735^{\mathrm{a}}$ & $10,775^{\mathrm{b}}$ & 654 & 0.0004 \\
\hline
\end{tabular}

SE, standard error.

${ }^{1}$ Means of 8 observations.

a,b Means with different superscripts within the same row are significantly different $(\mathrm{p}<0.05)$. 
Table 7. Amino acid composition of longissimus muscle of Hanwoo steers fed with trace mineral-fortified microbial culture (TMC) during the late fattening period (\%, DM basis) ${ }^{1}$

\begin{tabular}{lcccc}
\hline Item & Control & TMC added & SE & p-value \\
\hline Essential amino acids & & & & \\
Lysine & $5.5^{\mathrm{a}}$ & $5.9^{\mathrm{b}}$ & 0.1523 & 0.0321 \\
Leucine & $4.9^{\mathrm{a}}$ & $5.4^{\mathrm{b}}$ & 0.1918 & 0.0124 \\
Valine & $4.2^{\mathrm{a}}$ & $4.4^{\mathrm{b}}$ & 0.0904 & 0.0440 \\
Methionine & 3.8 & 4.0 & 0.0743 & 0.0853 \\
Threonine & 4.6 & 4.6 & 0.1082 & 0.4994 \\
Isoleucine & 4.3 & 5.0 & 0.4617 & 0.1517 \\
Arginine & 6.6 & 6.7 & 0.1545 & 0.4321 \\
Phenylalanine & 4.8 & 4.9 & 0.1089 & 0.3190 \\
Histidine & 4.3 & 4.4 & 0.1373 & 0.3779 \\
Non-essential amino acids & & & \\
Aspartic acid & 6.9 & 7.1 & 0.1438 & 0.1210 \\
Alanine & 5.0 & 5.2 & 0.0998 & 0.1013 \\
Serine & 4.1 & 4.2 & 0.0915 & 0.3551 \\
Glutamic acid & 9.1 & 9.4 & 0.2333 & 0.1853 \\
Proline & $18.5^{\mathrm{a}}$ & $15.0^{\mathrm{b}}$ & 1.5914 & 0.0438 \\
Glycine & 4.0 & 4.0 & 0.1042 & 0.6386 \\
Cysteine & 1.8 & 1.9 & 0.1514 & 0.6860 \\
Tyrosine & 4.5 & 4.4 & 0.0833 & 0.1984 \\
\hline
\end{tabular}

SE, standard error; DM, dry matter.

${ }^{1}$ Means of 8 observations.

${ }^{a, b}$ Means with different superscripts within the same row are significantly different $(\mathrm{p}<0.05)$

of certain essential amino acids in the longissimus muscle.

Most mammals can synthesize proline from arginine and glutamate, and proline and its metabolites constitute one-third of the amino acids in the collagen proteins, which provide the muscles with the strength and structure required for movement and general function (Wu et al., 2011). However, it is not currently clear why proline concentration decreased in the present study.

Meat fatty acid profile: Effect of TMC consumption on the fatty acid composition of the longissimus muscle is presented in Table 8. The fatty acid composition and saturated or unsaturated fatty acid ratios of the longissimus

Table 8. Fatty acid composition (DM basis) of longissimus muscle of Hanwoo steers fed with trace mineral-fortified microbial culture (TMC) during the late fattening period ${ }^{1}$

\begin{tabular}{lcccc}
\hline Item & Control & $\begin{array}{c}\text { TMC } \\
\text { added }\end{array}$ & SE & p-value \\
\hline Myristic acid $\left(\mathrm{C}_{14: 0}\right)$ & 3.88 & 3.93 & 0.18 & 0.7903 \\
Palmitic acid $\left(\mathrm{C}_{16: 0}\right)$ & 29.01 & 29.62 & 0.52 & 0.2702 \\
Palmitoleic acid $\left(\mathrm{C}_{16: 1)}\right.$ & 6.87 & 6.44 & 0.55 & 0.4546 \\
Stearic acid $\left(\mathrm{C}_{18: 0}\right)$ & 14.03 & 13.97 & 0.74 & 0.9458 \\
Oleic acid $\left(\mathrm{C}_{18: 1)}\right)$ & 46.21 & 46.03 & 1.03 & 0.8647 \\
Total saturated fatty acids & 46.92 & 47.53 & 0.98 & 0.5437 \\
Total unsaturated fatty acids & 53.08 & 52.47 & 0.98 & 0.5437 \\
\hline
\end{tabular}

DM, dry matter; SE, standard error.

${ }^{1}$ Means of 8 observations. muscle were not affected by the dietary treatment. Similarly, feeding probiotics with bentonite to beef cattle for 22 months did not affect the fatty acid composition of the longissimus muscle (Kwak et al., 2012).

In conclusion, TMC supplementation during the latefattening period enhanced the concentrations of certain trace minerals and essential amino acids in the longissimus muscle without inducing any deleterious effects on the performance and other carcass characteristics of Hanwoo steers.

\section{CONCLUSION}

The results of the present study indicate that TMC supplementation in the diet of late-fattening Hanwoo steers could be recommended to improve carcass weight, meat quality, and net income without negatively affecting animal health and carcass characteristics. The use of TMC in the beef cattle diet induced higher bioavailability of certain trace minerals and sulfur. Moreover, ingestion of the inorganic sulfate form of trace minerals improved the retention of certain essential amino acids in the muscle. Thus, TMC supplementation could aid in maintaining the health and welfare of beef steers.

\section{CONFLICT OF INTEREST}

We certify that there is no conflict of interest with any financial organization regarding the material discussed in the manuscript.

\section{ACKNOWLEDGMENTS}

This study was carried out with the support of the "Cooperative Research Program for Agriculture Science and Technology Development (Project No. PJ009382012015)", the Rural Development Administration, Republic of Korea.

\section{REFERENCES}

Adams, C. A. 2001. Total Nutrition: Feeding Animals for Health and Growth. 1st Ed. Nottingham University Press, Nottingham, UK.

Adams, D. C., M. L. Galyean, H. E. Kiesling, J. D. Wallace, and M. D. Finkner. 1981. Influence of viable yeast culture, sodium bicarbonate and monensin on liquid dilution rate, rumen fermentation and feedlot performance of growing steers and digestibility in lambs. J. Anim. Sci. 53:780-789.

AOAC. 2000. Official Methods of Analysis. 17th Ed. Association of Official Analytical Chemists, Washington, DC, USA.

Asplund, J. M. 1994. The influence of energy on amino acid supply and utilization in the ruminant. In: Principles of Protein Nutrition of Ruminants (Ed. J. Malcolm Asplund). CRC Press, Boca Raton, FL, USA. 
Braselton, W. E., K. J. Stuart, T. P. Mullaney, and T. H. Herdt. 1997. Biopsy mineral analysis by inductively coupled plasmaatomic emission spectroscopy with ultrasonic nebulization. J. Vet. Diagn. Invest. 9:395-400.

Cao, J., P. R. Henry, R. Guo, R. A. Holwerda, J. P. Toth, R. C. Littell, R. D. Miles, and C. B. Ammerman. 2000. Chemical characteristics and relative bioavailability of supplemental organic zinc sources for poultry and ruminants. J. Anim. Sci. 78:2039-2054.

Cole, N. A., C. W. Purdy, and D. P. Hutcheson. 1992. Influence of yeast culture on feeder calves and lambs. J. Anim. Sci. 70:1682-1690.

Greene, L. W., D. K. Lunt, F. M. Byers, N. K. Chirase, C. E. Richmond, R. E. Knutson, and G. T. Schelling. 1988. Performance and carcass quality of steers supplemented with zinc oxide or zinc methionine. J. Anim. Sci. 66:1818-1823.

Ishler, V., J. Heinrichs, and G. Varga. 1996. From Feed to Milk: Understanding Rumen Function. Extension Circular 422. College of Agricultural Sciences, The Pennsylvania State University, University Park, PA, USA.

Kim, K. S. and S. M. Lee. 2014. Effects of black sugar and mineral supplementation on growth performance and meat quality of Hanwoo steers in fattening period. J. Korean Soc. Grassland Forage Sci. 34:202-208.

Kim, S. H., S. H. Byun, S. M. Lee, J. H. Hwang, B. T. Jeon, S. H. Moon, and S. H. Sung. 2007a. Effects of supplementation period and levels of fermented mineral feed (Power-Mix) on the growth and carcass characteristics of Hanwoo steer. Korean J. Food Sci. Anim. Res. 27:450-456.

Kim, Y. I., S. H. Jeong, J. S. Seok, S. Y. Yang, J. W. Huh, and W. S. Kwak. 2008. Isolation and identification of hydrolytic enzymeproducing bacteria from spent mushroom substrate. Korean J. Anim. Sci. Technol. 50:713-720.

Kim, Y. I., S. H. Jung, J. S. Seok, S. Y. Yang, J. W. Huh, and W. S. Kwak. 2007b. Isolation and identification of high cellulolytic bacteria from spent mushroom substrate and determination of optimal medium conditions for the growth. Korean J. Microbiol. Biotechnol. 35:255-260.

Korean Feeding Standard Establishment Council. 2007. Korean Feeding Standard for Korean Cattle (Hanwoo). National Livestock Research Institute, RDA, Ministry of Agriculture and Forestry, Sejong, Korea.

Korean Ministry of Agriculture and Forest. 2007. Carcass grading standards. Livestock Regulation Practice, Appendix no. 4, KMAF, Sejong, Korea.

Krehbiel, C. R., S. R. Rust, G. Zhang, and S. E. Gilliland. 2003. Bacterial direct-fed microbials in ruminant diets: Performance response and mode of action. J. Anim. Sci. 81:E120-E132.

Kwak, W. S. and J. S. Kang. 2006. Effect of feeding food wastebroiler litter and bakery by-product mixture to pigs. Bioresour. Technol. 97:243-249.

Kwak, W. S., S. M. Lee, and Y. I. Kim. 2012. Effects of dietary addition of bentonite and probiotics on meat characteristics and health of Hanwoo (Bos taurus coreanae) steers fed rice straw as a sole roughage source: A field study. J. Korean Soc. Grassland Forage Sci. 32:387-396.
Mir, Z. and P. S. Mir. 1994. Effect of the addition of live yeast (Saccharomyces cerevisiae) on growth and carcass quality of steers fed high-forage or high-grain diets and on feed digestibility and in situ degradability. J. Anim. Sci. 72:537-545.

National Research Council. 1998. Nutrient Requirements of Swine. 10th Ed. National Academy Press, Washington, DC, USA.

National Research Council. 2000. Nutrient Requirements of Beef Cattle. Update 2000. National Academy Press, Washington, DC, USA.

National Research Council. 2005. Mineral Tolerance of Animals. 2nd Ed. National Academy Press, Washington, DC, USA.

Robinson, P. H. and J. E. Garrett. 1999. Effect of yeast culture (Saccharomyces cerevisiae) on adaptation of cows to postpartum diets and on lactational performance. J. Anim. Sci. 77:988-999.

Spears, J. W. 2003. Trace mineral bioavailability in ruminants. J. Nutr. 133:1506S-1509S.

Spears, J. W. and E. B. Kegley. 2002. Effect of zinc source (zinc oxide vs. zinc proteinate) and level on performance, carcass characteristics, and immune response of growing and finishing steers. J. Anim. Sci. 80:2747-2752.

Statistix7. 2000. User's Manual. Analytical Software, Tallahassee, FL, USA.

Underwood, E. J. and N. F. Suttle. 1999. The Mineral Nutrition of Livestock. 3rd Ed. CABI Publishing, New York, NY, USA.

Westing, T. W., J. P. Fontenot, W. H. McClure, R. F. Kelly, and K. E. Webb., Jr. 1985. Characterization of mineral element profiles in animal waste and tissues from cattle fed animal waste: 1. Heifers fed broiler litter. J. Anim. Sci. 61:670-681.

Williams, J. E., D. G. Wagner, L. E. Walters, G. W. Horn, G. R. Waller, P. L. Sims, and J. J. Guenther. 1983. Effect of production systems on performance, body composition and lipid and mineral profiles of soft tissue in cattle. J. Anim. Sci. 57:1020-1028.

Williams, P. E. V., C. A. G. Tait, G. M. Innes, and C. J. Newbold. 1991. Effects of the inclusion of yeast culture (Saccharomyces cerevisiae plus growth medium) in the diet of dairy cows on milk yield and forage degradation and fermentation patterns in the rumen of steers. J. Anim. Sci. 69:3016-3026.

Wu, G., F. W. Bazer, R. C. Burghardt, G. A. Johnson, S. W. Kim, D. A. Knabe, P. Li, X. Li, J. R. McKnight, M. C. Satterfield, and T. E. Spencer. 2011. Proline and hydroxyproline metabolism: Implications for animal and human nutrition. Amino Acids 40:1053-1063.

Yang, S. Y., K. S. Ji, Y. H. Baik, W. S. Kwak, and T. A. McCaskey. 2006. Lactic acid fermentation of food waste for swine feed. Bioresour. Technol. 97:1858-1864.

Yoon, I. K. and M. D. Stern. 1995. Influence of direct-fed microbials on ruminal microbial fermentation and performance of ruminants: A review. Asian Australas. J. Anim. Sci. 8:533555 .

Zhou, Q., K. Li, X. Jun, and L. Bo. 2009. Role and functions of beneficial microorganisms in sustainable aquaculture. Bioresour. Technol. 100:3780-3786. 